\title{
Differential expression of syndecan isoforms during mouse incisor amelogenesis
}

\author{
Taro Muto", Keiko Miyoshi", Seiichi Munesue ${ }^{3)}$, Hiroshi Nakada ${ }^{3)}$, Minoru Okayama", \\ Takashi Matsuo', and Takafumi Noma" \\ ${ }^{1)}$ Department of Molecular Biology, and Department of ${ }^{2}$ Conservative Dentistry, Institute of Health \\ Biosciences, The University of Tokushima Graduate School, Tokushima, Japan ; and ${ }^{3)}$ Department of \\ Biotechnology, Faculty of Engineering, Kyoto Sangyo University, Kyoto, Japan
}

\begin{abstract}
Syndecans are transmembranous heparan sulfate proteoglycans (HSPGs) with covalently attached glycosaminoglycan side-chains located on the cell surface. The mammalian syndecan family is composed of four types of syndecans (syndecan-1 to -4). Syndecans interact with the intracellular cytoskeleton through the cytoplasmic domains of their core proteins and membrane proteins, extracellular enzymes, growth factors, and matrix components, through their heparan-sulfate chains, to regulate developmental processes.

Here, as a first step to assess the possible roles of syndecan proteins in amelogenesis, we examined the expression patterns of all syndecan isoforms in continuously growing mouse incisors, in which we can overview major differentiation stages of amelogenesis at a glance. Understanding the expression domain of each syndecan isoform during specific developmental stages seems useful for investigating their physiological roles in amelogenesis.

Immunohistochemical analysis of syndecan core proteins in the lower incisors from postnatal day 1 mice revealed spatially and temporally specific expression patterns, with syndecan-1 expressed in undifferentiated epithelial and mesenchymal cells, and syndecan-2, $\mathbf{- 3}$, and $\mathbf{- 4}$ in more differentiated cells. These findings suggest that each syndecan isoform functions distinctly during the amelogenesis of the incisors of mice. J. Med. Invest. 54 : 331-339, August, 2007
\end{abstract}

Keywords : amelogenesis, immunohistochemistry, incisor, syndecan

\section{INTRODUCTION}

Syndecan is a HSPG that consists of core protein and covalently coupled glycosaminoglycan chains. It is a member of the type I transmembrane protein

Received for publication May 14, 2007 ; accepted July 17, 2007.

Address correspondence and reprint requests to Takafumi Noma, M.D., Ph.D., Department of Molecular Biology, Institute of Health Biosciences, The University of Tokushima Graduate School, Kuramoto-cho, Tokushima 770-8504, Japan and Fax : +8188-633-7326. family (1-3). There are four types of syndecan genes in mammals (Syndecan-1 to -4). Syndecan-1 is the major syndecan in epithelial cells. Syndecan-1 knockout mice show delayed cutaneous and corneal wound healing (4), as well as increased leukocyte-endothelial interactions, and angiogenesis (5). Syndecan-2 is predominates in fibroblasts. It regulates actin skeletal organization of the Lewis lung carcinoma-derived cells by interacting with fibronectin (6). Syndecan3 is abundant in neuronal cells, and syndecan-3 deficient mice show enhanced long-term potentiation 
and impaired hippocampus-dependent memory (7). Syndecan- 4 is widely distributed and is thought to be an important cell-surface receptor in wound healing and angiogenesis (8).

The core proteins of syndecans consist of extracellular, transmembrane, and cytoplasmic domains (9) (Fig. 1). Heparan-sulfate chains are linked to their extracellular domains $(2,3)$. These heparan sulfate glycosaminoglycan chains contribute specific properties to syndecan molecules, because they bind to and modulate the activity of extracellular matrix components, growth factors, and proteinase inhibitors, and are thought to influence many developmental processes including tooth morphogenesis $(2,3)$.

Amelogenesis is divided into three stages : presecretory, secretory, and maturation (10-12). The presecretory stage of amelogenesis is carried out by the epithelial cells facing dental pulp or dentin. The epithelial layer facing pulp is called the odontogenic organ, whereas that facing dentin is a part of the enamel organ. The odontogenic organ is further divided into posterior and anterior portions, which are characterized by the multiple and the single layers of outer dental epithelium, respectively. In the secretory stage, ameloblasts elongate their shape, secrete enamel proteins, and face the enamel matrix. Tome's processes appear at this stage. At the maturation stage, the ameloblasts become shorter and enamel matrix undergo degradation of residual proteins, removal of water, and deposition of calcium and phosphate for the final mineralization.

Previously, expression of syndecan- 1 and -2 was examined in mouse molars. Syndecan-1 expression was transiently seen in the enamel epithelium and the dental mesenchyme at the bud stage, and appeared again in the stratum intermedium and stellate reticulum at the bell stage (13-15). In contrast, the highest amounts of syndecan- 2 were observed at the bell stage. The strong expression is restricted to mesenchymal cells in the dental sac mesenchyme, and later to the alveolar bone and differentiating odontoblasts (16). However, the differential roles of syndecan isoforms during tooth amelogenesis has not been fully elucidated since (i) the distribution of HSPGs detected by anti-heparan sulfate antibody was not same as those of syndecan- 1 and -2 (16), but (ii) there are no reports on the other syndecan isoforms, syndecan-3 and -4 .

In this study, we determined the localization of all four syndecan isoforms to investigate their roles in amelogenesis by immunohistochemistry using lower incisors of postnatal day 1 mice. There are several advantages to use the incisors of postnatal day 1 mice as the experimental materials as follows, (i) it is unnecessary to wait for animals to be adult, (ii) the decalcification step of enamel organ, which takes long time and sometimes brings the artifacts or less sensitivity of the specific targets in immunohistochemical analysis of the organ, is dispensable, (iii) one can survey the major events of amelogenesis, from the proliferation of undifferentiated ameloblasts to the mineralization event of the enamel, at a glance. Thus, to determine the distribution of syndecans in the tissue of wild-type animals contribute to both studies to analyze the amelogenesis in the syndecan deficient animals, and to examine the distribution

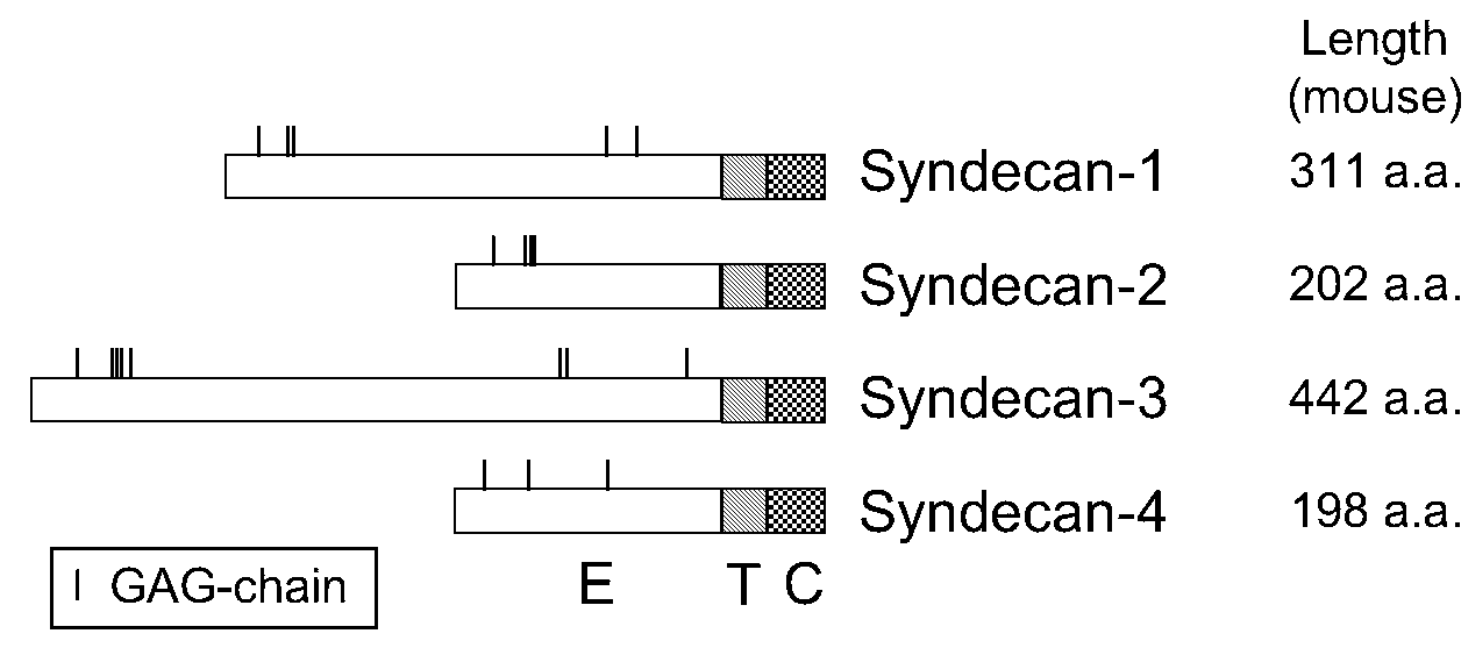

Fig. 1 Schematic representation of the domain organizations of syndecans

Domain structures, glycosaminoglycan (GAG) chain attachment sites, and the numbers of amino acid residues of syndecans are shown. E, T, and C indicate extracellular, transmembrane, and cytoplasmic domains, respectively. Vertical bars indicate the GAG attachment sites (9). 
of syndecans in animals deficient in amelogenesis. Our present study supplied the method to detect syndecans, and the normal controls of their expression patterns, as well as the possible roles of syndecans in amelogenesis are speculated.

\section{MATERIALS AND METHODS}

\section{Tissues and Antibodies}

Mandibles including incisors were excised from ICR mice at P1. The tissue samples were fixed with $4 \%$ paraformaldehyde in phosphate buffered saline (PBS) for $4 \mathrm{~h}$ at room temperature. For immunohistochemistry, $8-12-\mu \mathrm{m}$ sections of paraffin-embedded tissues were used.

Polyclonal rabbit IgG antibodies were raised against the extracellular domains of mouse syndecan- $1,-2$, -3 , and -4 (SN1Ab, SN2Ab, SN3Ab, and SN4Ab, respectively) (17). Pre-immune rabbit IgG was used as a control. Mice were maintained and treated in accordance with the guidelines for Animal Experiment at The University of Tokushima Graduate School, and the experimental protocols were approved by the Committee of the Ethics on Animal Experiment at The University of Tokushima Graduate School.

Reverse transcription-polymerase chain reaction (RT-PCR)

Lower jaws were excised from three ICR mice at postnatal day 1 (P1). Total RNA was extracted from the jaws using TRI reagent (MRC ; Cincinnati, $\mathrm{OH}$ ) by following the manufacturer's instructions. Total RNA from the jaws was reverse transcribed with oligo dT primer using an RNA PCR kit (AMV) ver. 3.0 (Takara Bio ; Ohtsu, Japan). Amplification of syndecans and GAPDH transcripts was done by an initial denaturing step of $94^{\circ} \mathrm{C}$ for 6 min followed by 40 cycles of polymerase chain reaction $(\mathrm{PCR})\left(94^{\circ} \mathrm{C}\right.$ for $30 \mathrm{~s}, 57^{\circ} \mathrm{C}$ for $30 \mathrm{~s}, 72^{\circ} \mathrm{C}$ for $1 \mathrm{~min}$ ), using Taq DNA polymerase (Promega; Madison, WI). The primers used were as follows : syndecan-1 forward : 5'-TCT GAC AAC TTC TCT GGC TCT GG-3', and reverse : 5'-GCT GTG TTC TCC CCA GAT GTT TC-3' (545 bp), syndecan-2 forward : 5'-CAC AGA CGT GTA CAC CGA GAA AC-3', and reverse : 5'CTG CTA TTC ACA GAA CAC TGC AGA TG-3' (444 bp), syndecan-3 forward : 5'-ACT AGA GCG GAA GGA GGT GCT C-3', and reverse : 5'-AAC CAG GGC TTC CTT CCT CTT G-3' (474 bp), syndecan-4 forward : 5'-TGC TGG CGG CTC GGA TGA CTT TG-3', and reverse : 5'-CTG CCA AGA
CCT CAG TTC TCT C-3' (290 bp), and GAPDH forward : 5'-CAT TGA CCT CAA CTA CAT GG-3', and reverse : 5'-CTC AGT GTA GCC CAG GAT GC-3' (724 bp). The PCR products were sequenced by an ABI PRISM 3100-Avant Genetic Analyzer (Applied Biosystems ; Lincoln Centre Drive, Foster City, $\mathrm{CA}$ ) using primers used for PCR amplification and their identities were confirmed.

\section{Immunohistochemistry}

Sections on glass slides were deparaffinized in xylene, and substituted with ethanol followed by PBS. Intrinsic alkaline phosphatase activity was removed by using $3 \%$ hydrogen peroxide in methanol for $20 \mathrm{~min}$ at room temperature. After treatment of the sections by microwave with antigen unmasking solution (Vector Laboratories Inc. ; Burlingame, $\mathrm{CA})$, sections were blocked with PBS supplemented with $4 \%$ bovine serum albumin (BSA) and $3 \%$ normal horse serum for $30 \mathrm{~min}$. Incubation of sections was performed with primary antibodies diluted with $1 \%$ BSA-PBS $(30 \mu \mathrm{g} / \mathrm{ml}$ for SN1Ab, SN2Ab, and SN4 $\mathrm{Ab}, 10 \mu \mathrm{g} / \mathrm{ml}$ for SN3Ab, and $1: 2000$ dilution for anti-collagen type IV antiserum) at $4^{\circ} \mathrm{C}$ overnight, followed by incubation with horseradish peroxidaselabeled anti-rabbit Ig polyclonal antibody (Histofine Simple Stain Rat MAX-PO (R)) (Nichirei ; Tokyo, Japan). Finally, peroxidase activity was developed in Histofine Simple Stain DAB solution (Nichirei). The sections were counterstained with hematoxylin, dehydrated, and mounted. Sections from three to five mice were examined for each staining.

\section{RESULTS}

$R T$-PCR analysis of syndecan expression in the mandibles of $P 1$ mice

Prior to the immunohistochemical analyses of syndecans, the expression of syndecans in the mandibles of ICR mice at P1 was examined by RT-PCR, the most sensitive system to detect gene expression. The mandibles contain apical loops, immature and mature enamel organs, dental pulp, and the surrounding epithelial cells of the continuously growing incisors. Total RNA was extracted from the mandibles, and RT-PCR analysis was performed to examine which syndecans were expressed. Specific PCR products were obtained from each reaction, indicating that all syndecan genes are expressed in the mandibles of P1 mice (Fig. 2). 


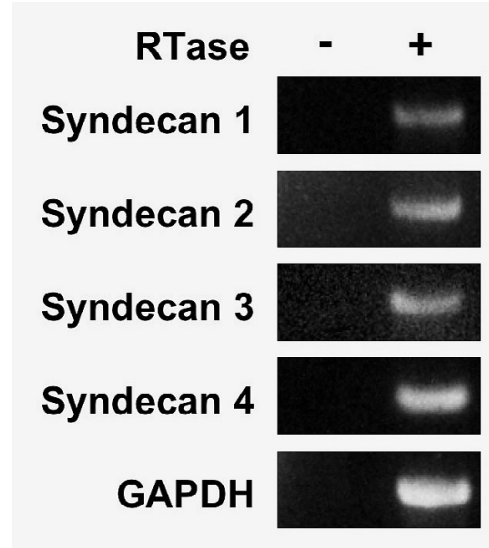

Fig. 2 RT-PCR analysis of syndecan expression in mandibles PCR amplification of syndecan cDNAs (syndecan-1 to -4) from the mandibles of P1 mice. GAPDH was amplified as a control. RTase : reverse transcriptase treatment for preparation of the cDNA template.

Localization of mouse syndecan core proteins in the lower incisors

The fact that each syndecan gene was expressed in the mandibles led us to study the immunohistochemical localization of syndecans in the tissues, especially in the incisors, in which all stages of amelogenesis can be seen in one section. Tissue slices along the longitudinal axis of incisors were stained with rabbit polyclonal antibodies raised against extracellular portions of mouse syndecan core proteins. The specificity of the antibodies was confirmed in the previous study $(17,18)$.

Syndecan-1 was detected inside the apical loop and the surrounding region (Fig. 3a). In the anterior portion of the odontogenic organ in the presecretory stage, syndecan-1 was strongly detected in inner enamel epithelium (ameloblasts), stratum intermedium, and outer enamel epithelium (Fig. 3a and f). In pulp, most of the cells expressed syndecan1, but pre-odontoblasts did not (Fig. 3a). In addition, the cells surrounding the outer enamel epithelium strongly expressed syndecan-1 (Fig. 3a). In the presecretory stage of the enamel organ, no syndecan1 staining was observed in ameloblasts or odontoblasts (Fig. 3a). Stratum intermedium and outer enamel epithelium were strongly stained with antisyndecan-1 antibody (Fig. 3a). Moreover, the pulp and the cells surrounding the outer enamel epithelium moderately expressed syndecan-1 (Fig. 3a). In the secretory stage, syndecan-1 staining was detected in the stratum intermedium, the papillary cells, and their surrounding cells, while no syndecan1 staining was seen in ameloblasts or odontoblasts
(Fig. 3a and k). In the maturation stage, syndecan-1 staining was detected in the stratum intermedium, the papillary cells and their surrounding cells, and not in the ameloblasts or odontoblasts (Fig. 3a).

In contrast to syndecan-1, expression of syndecan2 was slightly detected in the apical loop and in the cells surrounding the apical loop (Fig. 3b). In the anterior portion of the odontogenic organ in the presecretory stage, syndecan- 2 was slightly stained in the inner enamel epithelium (Fig. 3b and $\mathrm{g}$ ). In the presecretory stage of the enamel organ, syndecan- 2 was detected in ameloblasts, especially in the nuclei and the apical side, the stratum intermedium, and the outer enamel epithelium; however, there was no staining in the stellate reticulum (Fig. $3 \mathrm{~b}$ ). In odontoblasts and the surrounding cells of the outer enamel epithelium, syndecan- 2 was moderately stained, and a little expression was observed in the pulp (Fig. 3b). In the secretory and maturation stages, syndecan-2 was strongly detected in ameloblasts, odontoblasts, and the stratum intermedium, and slightly in the papillary cells, their surrounding cells, and the pulp (Fig. $3 b$ and 1 ).

Expression of syndecan-3, similar to syndecan-2, was slightly detected in the apical loop and the surrounding dental pulp (Fig. 3c). Moreover, syndecan3 was barely observed in the inner enamel epithelium in the anterior portion of the odontogenic organ in the presecretory stage (Fig. $3 \mathrm{c}$ and $\mathrm{h}$ ). In the presecretory stage of the enamel organ, syndecan-3 was stained in ameloblasts (nuclei and cytosol), the stratum intermedium, and the outer enamel epithelium (Fig. 3c). In addition, syndecan-3 was expressed in odontoblasts and the surrounding cells of the outer enamel epithelium, and was slightly detected in the pulp (Fig. 3c). In the secretory and maturation stages, syndecan-3 was detected in ameloblasts, odontoblasts, the stratum intermedium, the papillary cells and their surrounding cells, and the pulp (Fig. $3 \mathrm{c}$ and $\mathrm{m}$ ).

Syndecan- 4 expression contrasts with syndecan- 1 and is similar to that of both syndecan- 2 and -3 , with some distinctions. Little expression was observed in the apical loop, the surrounding dental pulp (Fig. 3d), and the inner enamel epithelium in the anterior portion of the odontogenic organ in the presecretory stage (Fig. $3 \mathrm{~d}$ and i). In the presecretory stage of the enamel organ, syndecan- 4 was slightly stained in this region (Fig. 3d). In the secretory stage, syndecan- 4 was stained in ameloblasts, odontoblasts, the stratum intermedium, and the pulp. 
However, no staining was seen in the papillary cells and their surrounding cells (Fig. $3 \mathrm{~d}$ and $\mathrm{n}$ ). In the maturation stage, syndecan- 4 was stained strongly in ameloblasts (Fig. 3d). The staining of syndecan- 4 was detected in ameloblasts, and modestly detected in odontoblasts, papillary cells, and the pulp region
(Fig. 3d). Further, no syndecan-4 staining was seen in the cells surrounding the papillary cells (Fig. 3d).

Incisor tissue sections were also stained with normal rabbit IgG as a negative control for the immunohistochemistry (Fig. 3e, j, and o). The summary of syndecan expression is shown in Table 1 .
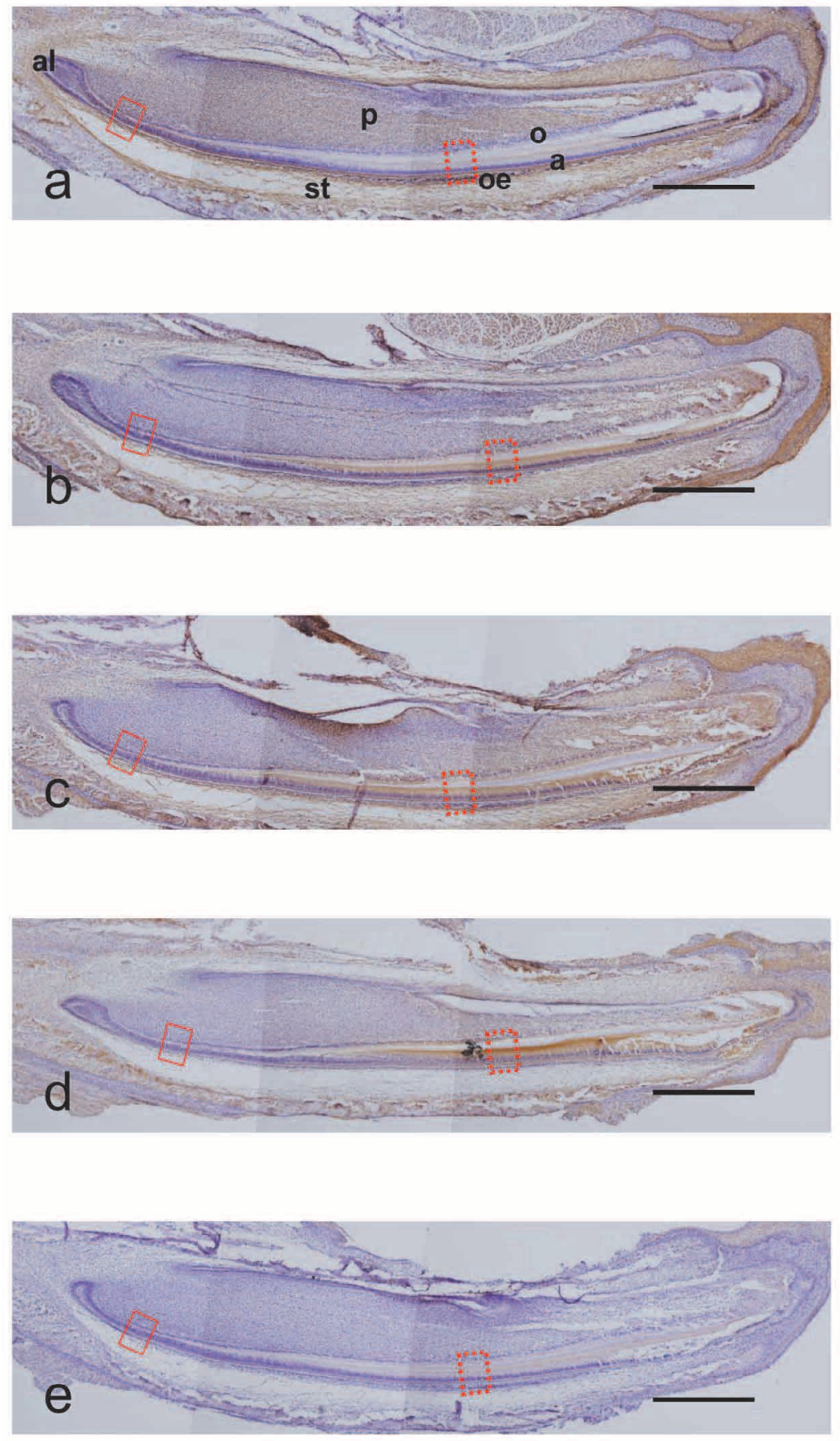
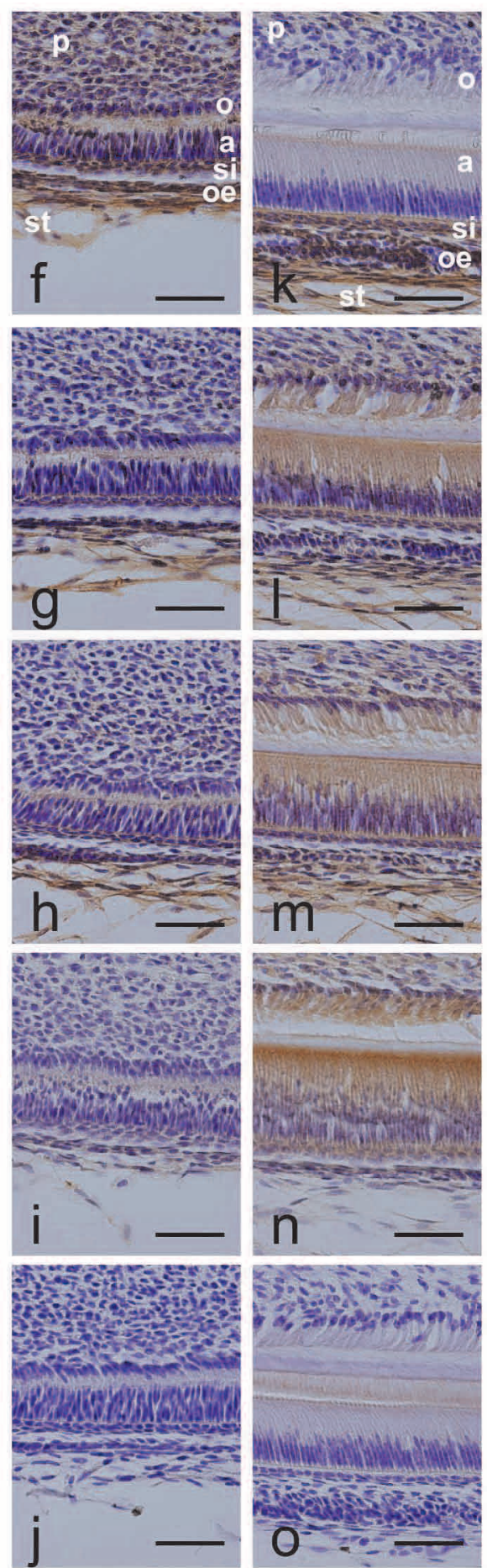

Fig. 3 Immunohistochemical examination of syndecan expression in mouse incisors at P1

Anti-syndecan-1 (a, f, k), -2 (b, g, 1), -3 (c, h, m), and -4 (d, i, n) antibodies, and normal IgG (e, j, o) staining of lower incisors from P1 mice. (a-e) Overview of the incisors. (f-o) Higher magnification of odontogenic regions of the presecretory stage (f-j), and the secretory stage (k-o) of incisors, as indicated in the red solid and dotted boxes in (a-e), respectively. The surrounding architectures are indicated as follows : al : apical loop, $\mathrm{p}:$ dental pulp, oe : outer enamel epithelium, a: ameloblasts, o : odontoblasts, si : stratum intermedium, st : stellate reticulum. Scale bars : $500 \mu \mathrm{m}$ (a-e), or $50 \mu \mathrm{m}$ (f-o). 
Table 1 Summary of syndecan expression detected in mouse lower incisors by IHC

\begin{tabular}{|c|c|c|c|c|c|c|}
\hline & \multirow[t]{3}{*}{ Stages } & \multicolumn{3}{|c|}{ Presecretory } & \multirow[t]{3}{*}{ Secretory } & \multirow[t]{3}{*}{ Maturation } \\
\hline & & \multicolumn{2}{|c|}{ Odontogenic organ } & \multirow[t]{2}{*}{ Enamel organ } & & \\
\hline & & (Posterior) & (Anterior) & & & \\
\hline \multirow[t]{4}{*}{ Amleloblasts } & Syndecan-1 & + & + & - & - & - \\
\hline & Syndecan-2 & $+/-$ & $+/-$ & + & + & + \\
\hline & Syndecan-3 & $+/-$ & - & + & + & + \\
\hline & Syndecan-4 & $+/-$ & - & $+/-$ & + & + \\
\hline \multirow[t]{4}{*}{ Odontoblasts } & Syndecan-1 & & $+/-$ & - & - & - \\
\hline & Syndecan-2 & & $+/-$ & + & + & + \\
\hline & Syndecan-3 & & $+/-$ & + & + & + \\
\hline & Syndecan-4 & & $+/-$ & $+/-$ & + & + \\
\hline
\end{tabular}

\begin{tabular}{lcccc}
\hline & \multicolumn{4}{c}{ Regions } \\
\cline { 2 - 5 } & $\mathrm{Dp}$ & $\mathrm{Oe}$ & $\mathrm{Si}$ & $\mathrm{Pc}$ \\
\hline Syndecan-1 & + & + & + & + \\
Syndecan-2 & $+/-$ & + & + & + \\
Syndecan-3 & $+/-$ & + & + & + \\
Syndecan-4 & $+/-$ & - & + & - \\
\hline
\end{tabular}

$+:$ expression detected

+/- : expression detected only after enhancement of the signal

- : expression not detected

"Al : Apical loops, Dp : Dental pulp, Oe : Outer enamel epithelium,"

"Si, Stratum intermedium, Pc : Papillary cells"

\section{DISCUSSION}

Cell surface HSPGs have been thought to play important roles in modulation of the development of multicellular organisms, because of their strategic distribution at the cell surface and their wide functions, as well as their potential to interact with a variety of molecules such as extracellular matrix, growth factors, and their receptors $(2,3)$. All four syndecan isoforms are expressed at specific stages of embryonic development and in distinct places in mammals (3). For example, lung mesenchyme loses syndecan-1 expression and initiates syndecan-2 expression coincidently with the budding of epithelial bronchus (19).

In this study, we found that syndecan-1 expression in the inner enamel epithelium is restricted to presecretory zone where the epithelial cells face to mesenchymal cells, and disappears in more differentiated and maturated zones such as secretory and maturation stages, whereas syndecan- $2,-3$, and -4 expression become stronger in ameloblasts in secretory and maturation stages. Our findings of syndecan expression patterns are similar to those found in various types of tissue morphogenesis, indicating possible roles of syndecans in amelogenesis.

Our data demonstrated that the expression patterns of syndecan- $2,-3$, and -4 in mouse lower incisors are similar. They were expressed in odontoblasts and ameloblasts in secretory and maturation stages, and in the dental pulp. In addition, they were expressed in the stratum intermedium. These expression patterns suggest that syndecans may have redundant roles in tooth development, consistent with the previous finding of no gross abnormalities in syndecan- 4 deficient mice. The finding that there are several types of heparan sulfate chains in developing mouse molars (16) also supports the redundant model of syndecans in tooth development.

However, syndecans in the same regions of incisors may also have distinct roles in tooth morphogenesis, as demonstrated by the previous studies. Both syndecan- 2 and -3 are expressed in neurons of developing forebrain of rat, but have different functions $(20,21)$. In neurons, syndecan- 2 is located in synaptic junctions and is considered to contribute to tight cell-cell adhesion at these sites (20), whereas syndecan- 3 is seen in growth cones and axons, and thought to be concerned with neural outgrowth (21).

Syndecan-1 expression, which is detected in the region where the inner enamel epithelium faces mesenchymal cells (the odontogenic organ in presecretory stage), but not in the later stages, correlates with the presence of basement membrane between the epithelial and mesenchymal cells of the 
enamel organ. Previous findings demonstrated that both collagen type IV and HSPG are the components of the basement membrane at the incisors (22-24), and collagen type IV in the basement membrane of the enamel organ is removed and degraded by differentiating ameloblasts by means of their engulfing system (25), and the $72 \mathrm{kDa}$ type IV collagenase (MMP-2) secreted by odontoblasts is also thought to participate in the degradation of the dental basement membrane (26-28). Differentiating ameloblasts may decrease the expression of syndecan-1, a possible component of the basement membrane. Alternatively, restricted localization of syndecan-1 in the immature zone may enable the maturation of ameloblasts and odontoblasts, because disappearance of the basement membrane located between them enables the interaction between epithelium and mesenchyme (29) that is necessary for maturation of the enamel organ.

HSPGs bind to a wide variety of growth factors using their heparan sulfate chains with different moieties. Their binding to growth factors such as fibroblast growth factor, Wnt, and transforming growth factor- $\beta$ (TGF- $\beta$ ) family are known to be critical for tissue development (30-35). For example, during tooth development, several members of the TGF- $\beta$ family are known to be necessary to complete amelogenesis. TGF- $\beta 1$, and bone morphogenic protein (BMP) 2 are shown to induce in vitro ameloblast differentiation (36). In addition, BMP4 is necessary for ameloblast differentiation and enamel formation (37). Moreover, it is known that dental pulp in continuously erupting rat incisors expresses at least fourteen genes belonging to the TGF- $\beta$ superfamily (38). These findings, together with the expression patterns of syndecan-2, -3 , and -4 in the secretory and maturation stages of enamel organ, suggest that these syndecans may contribute to amelogenesis via supporting the activities of these growth factors. This scenario supports the expression pattern of syndecan- $2,-3$, and -4 in ameloblasts in the later portion of presecretory stage, which precedes the mineralization of enamel. Alternatively, syndecans themselves may regulate ameloblast differentiation, using their potential activity as transcriptional regulators after releasing the intracellular domain by protease cleavage of intramembrane domains like the notch/delta system (39). Another finding also indicate the possible role of syndecan-4 in amelogenesis through its negative regulation activity for ATF2, a member of activating transcription factor (ATF) subfamily (40), of which phos- phorylated form is restricted to secretory to transition zones (41).

In conclusion, we found reciprocal and redundant expression patterns of syndecan isoforms in the continuously erupting mouse incisors, in which we can survey the whole steps of amelogenesis, from the apical to the incisal end. The results suggest that the syndecan isoforms have both distinct and redundant roles in amelogenesis. The molecular basis of these roles during tooth development remains to be determined as a next step.

\section{ACKNOWLEDGMENTS}

This work was partly supported by grants-in-aid for scientific research (Nos. 17659598, 18791368, and 17689051) from the Ministry of Education, Culture, Sports, Science and Technology of Japan. We thank Drs. T. Horiguchi, K. Abe, Intan Ruspita, K. Fujisawa and P. Yamaguchi for helpful discussions, and Ms. M. Sawatari for her secretarial help. We also thanks to Prof. Y. Hayashi, Mr. A. Kanaya, Mr. H. Niki and Mr. K. Sukegawa for their kind support.

\section{REFERENCES}

1. Couchman JR: Syndecans : proteoglycan regulators of cell-surface microdomains? Nat Rev Mol Cell Biol 4 : 926-937, 2003

2. Rapraeger AC : Molecular interactions of syndecans during development. Semin Cell Dev Biol 12 : 107-116, 2001

3. Bernfield M, Kokenyesi R, Kato M, Hinkes MT, Spring J, Gallo RL, Lose EJ : Biology of the syndecans : a family of transmembrane heparan sulfate proteoglycans. Annu Rev Cell Biol 8 : 365393, 1992

4. Stepp MA, Gibson HE, Gala PH, Iglesia DD, Pajoohesh-Ganji A, Pal-Ghosh S, Brown M, Aquino C, Schwartz AM, Goldberger O, Hinkes MT, Bernfield M : Defects in keratinocyte activation during wound healing in the syndecan1-deficient mouse. J Cell Sci 115 : 4517-4531, 2002

5. Gotte M, Joussen AM, Klein C, Andre P, Wagner DD, Hinkes MT, Kirchhof B, Adamis AP, Bernfield $\mathrm{M}$ : Role of syndecan-1 in leukocyteendothelial interactions in the ocular vasculature. Invest Ophthalmol Vis Sci 43 : 1135-1141, 
2002

6. Kusano Y, Oguri K, Nagayasu Y, Munesue S, Ishihara M, Saiki I, Yonekura H, Yamamoto $\mathrm{H}$, Okayama $\mathrm{M}$ : Participation of syndecan 2 in the induction of stress fiber formation in cooperation with integrin alpha5beta 1 : structural characteristics of heparan sulfate chains with avidity to $\mathrm{COOH}$-terminal heparin-binding domain of fibronectin. Exp Cell Res 256 : 434444, 2000

7. Kaksonen M, Pavlov I, Voikar V, Lauri SE, Hienola A, Riekki R, Lakso M, Taira T, Rauvala $\mathrm{H}$ : Syndecan-3-deficient mice exhibit enhanced LTP and impaired hippocampus-dependent memory. Mol Cell Neurosci 21 : 158-172, 2002

8. Echtermeyer F, Baciu PC, Saoncella S, Ge Y, Goetinck PF : Syndecan- 4 core protein is sufficient for the assembly of focal adhesions and actin stress fibers. J Cell Sci 112 (Pt 20) : 34333441, 1999

9. Zimmermann P, David G : The syndecans, tuners of transmembrane signaling. Faseb J 13 (Suppl) : S91-S100, 1999

10. Ten Cate A, Sharpe P, Roy S, Nanci A: Development of the tooth and its supporting tissues. In : Nanci A, ed. Ten Cate's Oral Histology : Development, Structure, and Function (Ten Cate's Oral Histology). Mosby, Missouri, 2003, pp. $79-110$

11. Nanci A: Enamel: Composition, formation, structure. In : Nanci A, ed. Ten Cate's Oral Histology : Development, Structure, and Function (Ten Cate's Oral Histology). Mosby, Missouri, 2003, pp. 145-191

12. Warshawsky H, Smith CE : Morphological classification of rat incisor ameloblasts. Anat Rec 179 : 423-446, 1974

13. Thesleff I, Jalkanen M, Vainio S, Bernfield M : Cell surface proteoglycan expression correlates with epithelial-mesenchymal interaction during tooth morphogenesis. Dev Biol 129 : 565572,1988

14. Vainio S, Jalkanen M, Thesleff I : Syndecan and tenascin expression is induced by epithelialmesenchymal interactions in embryonic tooth mesenchyme. J Cell Biol 108 : 1945-1953, 1989

15. Vainio S, Jalkanen M, Vaahtokari A, Sahlberg C, Mali M, Bernfield M, Thesleff I : Expression of syndecan gene is induced early, is transient, and correlates with changes in mesenchymal cell proliferation during tooth organogenesis. Dev Biol 147 : 322-333, 1991
16. Bai XM, Van der Schueren B, Cassiman JJ, Van den Berghe H, David G : Differential expression of multiple cell-surface heparan sulfate proteoglycans during embryonic tooth development. J Histochem Cytochem 42 : 10431054, 1994

17. Kusano Y, Yoshitomi Y, Munesue S, Okayama $\mathrm{M}$, Oguri $\mathrm{K}$ : Cooperation of syndecan-2 and syndecan-4 among cell surface heparan sulfate proteoglycans in the actin cytoskeletal organization of Lewis lung carcinoma cells. J Biochem (Tokyo) $135:$ 129-137, 2004

18. Akita K, Fushiki S, Fujimoto T, Munesue S, Inoue M, Oguri K, Okayama M, Yamashina I, Nakada $\mathrm{H}$ : Identification of the core protein carrying the Tn antigen in mouse brain : specific expression on syndecan-3. Cell Struct Funct $26: 271-278,2001$

19. Brauker JH, Trautman MS, Bernfield M : Syndecan, a cell surface proteoglycan, exhibits a molecular polymorphism during lung development. Dev Biol 147 : 285-292, 1991

20. Hsueh YP, Sheng M : Regulated expression and subcellular localization of syndecan heparan sulfate proteoglycans and the syndecan-binding protein CASK/LIN-2 during rat brain development. J Neurosci 19 : 7415-7425, 1999

21. Kinnunen A, Kinnunen T, Kaksonen M, Nolo $\mathrm{R}$, Panula $\mathrm{P}$, Rauvala $\mathrm{H}$ : N-syndecan and HBGAM (heparin-binding growth-associated molecule) associate with early axonal tracts in the rat brain. Eur J Neurosci 10 : 635-648, 1998

22. Murray IC, Leblond CP : Immunoelectron microscopy of endothelial cells in rat incisor suggests that most basement membrane components are produced by young cells, whereas heparan sulfate proteoglycan is produced by both young and old cells. J Histochem Cytochem 36 : 763-773, 1988

23. Laurie GW, Leblond CP, Cournil I, Martin GR : Immunohistochemical evidence for the intracellular formation of basement membrane collagen (type IV) in developing tissues. J Histochem Cytochem $28: 1267-1274,1980$

24. Laurie GW, Leblond CP, Martin GR: Localization of type IV collagen, laminin, heparan sulfate proteoglycan, and fibronectin to the basal lamina of basement membranes. J Cell Biol 95 : 340-344, 1982

25. Sawada T, Yamamoto T, Yanagisawa T, Takuma $\mathrm{S}$, Hasegawa $\mathrm{H}$, Watanabe $\mathrm{K}$ : Evidence for uptake of basement membrane by differenti- 
ating ameloblasts in the rat incisor enamel organ. J Dent Res 69 : 1508-1511, 1990

26. Sahlberg C, Reponen P, Tryggvason K, Thesleff $\mathrm{I}$ : Association between the expression of murine $72 \mathrm{kDa}$ type IV collagenase by odontoblasts and basement membrane degradation during mouse tooth development. Arch Oral Biol 37 : 10211030, 1992

27. Heikinheimo K, Salo T : Expression of basement membrane type IV collagen and type IV collagenases (MMP-2 and MMP-9) in human fetal teeth. J Dent Res 74 : 1226-1234, 1995

28. Kjoelby M, Thesleff I, Sahlberg C, Fejerskov O, Josephsen K: Degradation of the dental basement membrane during mouse tooth development in vitro. Int J Dev Biol 38 : 455-462, 1994

29. Brownell AG, Slavkin HC : Role of basal lamina in tissue interactions. Ren Physiol $3: 193$ 204, 1980

30. Bernfield M, Gotte M, Park PW, Reizes O, Fitzgerald ML, Lincecum J, Zako M : Functions of cell surface heparan sulfate proteoglycans. Annu Rev Biochem 68 : 729-777, 1999

31. Rapraeger AC:In the clutches of proteoglycans : how does heparan sulfate regulate FGF binding? Chem Biol 2 : 645-649, 1995

32. Perrimon $N$, Bernfield $M:$ Specificities of heparan sulphate proteoglycans in developmental processes. Nature $404: 725-728,2000$

33. Allen BL, Rapraeger AC: Spatial and temporal expression of heparan sulfate in mouse development regulates FGF and FGF receptor assembly. J Cell Biol 163 : 637-648, 2003

34. Viviano BL, Paine-Saunders S, Gasiunas N, Gallagher J, Saunders S : Domain-specific modification of heparan sulfate by Qsulf1 modu- lates the binding of the bone morphogenetic protein antagonist Noggin. J Biol Chem 279 : 5604-5611, 2004

35. Norton WH, Ledin J, Grandel H, Neumann CJ : HSPG synthesis by zebrafish Ext2 and Extl3 is required for Fgf10 signalling during limb development. Development 132 : 4963-4973, 2005

36. Coin R, Haikel Y, Ruch JV : Effects of apatite, transforming growth factor beta-1, bone morphogenetic protein-2 and interleukin-7 on ameloblast differentiation in vitro. Eur J Oral Sci 107 : 487495, 1999

37. Wang XP, Suomalainen M, Jorgez CJ, Matzuk MM, Werner S, Thesleff I : Follistatin regulates enamel patterning in mouse incisors by asymmetrically inhibiting BMP signaling and ameloblast differentiation. Dev Cell 7 : 719-730, 2004

38. Nakashima M, Toyono T, Murakami T, Akamine A : Transforming growth factor-beta superfamily members expressed in rat incisor pulp. Arch Oral Biol 43 : 745-751, 1998

39. Schulz JG, Annaert W, Vandekerckhove J, Zimmermann P, De Strooper B, David G : Syndecan 3 intramembrane proteolysis is presenilin/gamma-secretase-dependent and modulates cytosolic signaling. J Biol Chem 278 : 4865148657, 2003

40. Saoncella S, Calautti E, Neveu W, Goetinck PF : Syndecan- 4 regulates ATF-2 transcriptional activity in a Rac1-dependent manner. J Biol Chem 279 : 47172-47176, 2004

41. Nishikawa $\mathrm{S}$ : Transient increase in anti-pATF2 immunoreactivity in the late secretion ameloblasts apical to the transition zone of rat incisors. Anat Sci Int 79 : 87-94, 2004 